\title{
Study on Risks and Benefits Caused by Commercial Bank Loan Pricing for Small and Medium-sized Enterprises
}

\author{
Lulu Hao *, Jing Gao \\ Wuhan Business University, Wuhan, P.R.China, 430070 \\ haolulu8870@126.com
}

\begin{abstract}
The expected payment of making loan to SMEs for commercial bank is jointly determined by interest rate and the probability of enterprise's repayment. This paper firstly analyzes the effect of loan interest rate on enterprise's risks on the basis of constructing game model of the loan relationship between the bank and enterprise. And then the expected revenue function of commercial bank for making loan to SMEs is built and analyzed. According to the research results, the default risk of SMEs will go up in pace with the improvement of loan interest rate on the premise of the lack of effective collaterals. In addition, the effects of change in loan interest rate on the expected payment of commecial bank can be divided into two parts: income effect and risk effect, and there exits an optimal loan interest rate for commercial bank to realize the revenue maximization under a certain condition. Finally, the paper puts forward some suggestions on effectively controlling credit risks of SMEs and maximizing returns, including innovating on mortgage system and improving the system of loan pricing.
\end{abstract}

Keywords: Commercial bank; SMEs; defalut risk; expected revenue; loan interest rate; collaterals

\section{Introduction}

The practice of China's growth since the policy of reform and opening up has shown that small and medium-sized enterprises (SMEs) are not only an inexhaustible driving force for the healthy development of Chinese economy and improvement of technological innovation capability, but they also play an important role in stabilizing social employment and promoting social harmony. As the disadvantaged group in the market competition, however, the SMEs in China face many problems in pace with their rapid growth, such as insufficient funds and poor management. And the financing difficulties have been the foremost factor of hindering the development of SMEs since the global financial crisis in 2008 .

On the other hand, since the people's bank of China deregulated interbank lending rates in 1996, China has begun the reform process of RMB interest rate liberalization. However, the commercial bank has always just been the recipient and implementer of the given interest rates because of the government control, which then results in commercial bank's weak capacity of loan pricing. In addition, RMB interest rate liberalization will decrease the interest rate spreads between deposit and loan of Chinese banking industry, and the profit model that commercial bank relies on to survive is therefore hit. To get over the loss caused by the decrease of interest revenue, many experts have pointed out that commercial bank ought to expand its business in SMEs loan as well as vigorously develop the intermediary business. The commercial bank can achieve sustainable profitability and development in the increasing competition in the banking by means of exploring high-quality customers among SMEs, which can respond to the government's policy to support SMEs at the same 
time.

Based on the above background, the commercial bank in China is now facing a big test on its ability of loan pricing for SMEs. As many scholars say, the bank's expected payment of making loan to the enterprise is determined not only by loan interest rate but also by the default risk of the borrowing enterprise. It is not wise for commercial bank to raise the loan interest rate for revenue increasement because of the existence of enterprose's credit risks, namely adverse selection and moral hazard. Since the loan business is the main source of revenue, it is important for commercial bank to achieve a balanced relationship between risks and benefits of the loan, and the reasonable loan pricing is then the key point. For commercial bank, setting reasonable loan interest rates for SMEs can greatly help to improve the efficiency of capital allocation and expand credit business as well as realize the maximization of its revenue. If the bank blindly pursues high loan interest rates, however, it will lose a large number of high-quality customers, which then results in the decline in loan quality and serious credit risks.

According to the above statement, this paper will set its research emphasis on the risks and benefits caused by commercial bank loan pricing for SMEs by constructing relevant game model and mathematical model. Specifically, this paper will firstly analyze the effect of loan interest rate on enterprise's risks, including adverse selection and moral hazard, on the basis of constructing game model of the loan relationship between the bank and enterprise. And then the expected revenue function of commercial bank will be built, aiming at obtaining the optimal loan interest rate to realize the revenue maximization.

\section{Literature Review}

According to the existing literature, many scholars all over the world have conducted a great deal of empirical study and theoretical analysis on the relationship between loan interest rate and enterprise's default risk. Besides, the problem of how to factor enterprise's default risk into the bank loan pricing has also attracted the attention of many scholars.

Friedson, etc. (1997) have carried out an empirical analysis on the relationship between real interest rates and enterprises' default rates on high-yield bonds based on relevant data from 1971 to 1995 , and it is found that there is a positive correlation between them. In view of the credit rationing in markets with imperfect information, Helmut (1985) has pointed out that high-risk enterprises prefer the loan contracts with high interest rates and low-value collaterals, while low-risk enterprises favour the contracts with relatively low interest rates and high-value collaterals. Ewert, etc. (2000) made an empirical analysis on determinants of bank lending performance in Germany based on the sample comprised of a randomly chosen cross-section of 260 borrowers over the seven years from 1992 to 1998, and it was put forward that the credit rating is an important factor in loan pricing of the bank, namely, lower credit ratings reflecting higher risks lead to higher loan interest rates. Liu Chenxi (2012) conducted an empirical analysis on factors affecting commercial bank's rate floating amount based on data from public listing companies from 1999 to 2010, and the result has shown that the default rate of the company does not have a significant effect on the interest rate decided by commercial banks. Wei Jianguo and Zhu Chun (2013) have made a study on loan's credit risk identification and management of the village bank in China with the method of game theory. According to the analysis, village bank's loan interest rate 
is positively correlated with the probability that the borrower belongs to the low-quality type, namely, positively correlated with the risk of the borrower.

Considering that theoretical study on the effect of loan interest rate on enterprise's default risk in the existing literature remains to be further developed, the analysis on the risks and benefits caused by commercial bank loan pricing for SMEs with the method of game theory and mathematical tool in this paper will be an important complement to the current research.

\section{Game Analysis on the Loan Relationship Between Enterprise and Commercial Bank}

\subsection{Basic assumptions and parameters setting}

To construct the game model of the loan relationship between commercial bank and small or medium-sized enterprise, the following basic assumptions are made first.

(1) There are only two participants in the game, namely commercial bank and small or medium-sized enterprise. Information asymmetry exists between commercial bank and enterprise, and the bank therefore can't accurately judge the payment and risk corresponding to each optional project of the enterprise. Moreover, all of the optional investment projects of the enterprise can generate the same returns denoted by $R$, and this information is shared between the two participants.

(2) The optional investment projects faced by enterprise can form a continuous sequence and require the same capital represented by $D$. The enterprise can only invest the borrowed money in one project. What's more, the self-possessed funds of enterprise are set to be 0 , and the commercial bank is the sole capital provider for enterprise.

(3) Whether the enterprise repays the loan depends on the result of its project investment. To be specific, if the project investment succeeds, the enterprise will repay the loan on time. When the investment fails, however, the enterprise will default on the loan.

(4) This paper will focus on the mortgage loan of SMEs. Since the risks and benefits caused by commercial bank loan pricing are the research emphases in this paper, many factors like punishment for enterprise's default and relevant lawsuit are not considered in the analysis.

Symbols are set for other parameters involved as follows: the enterprise's loan interest rate decided by commercial bank is $i$. Return rate for the bank to carry out safe investments like buying treasury bonds is $r_{f}$. The value of collaterals provided by enterprise for the bank is denoted by $C$. The project investment of enterprise can succeed at a probability of $P$ with a return rate $r$, and all of relevant costs except loan interest rate have been deducted to get the rate $r$.

\subsection{Game analysis on the loan relationship between enterprise and commercial bank}

During the first stage of game playing, the enterprise has to decide whether to apply for the bank loan. If the enterprise decides not to borrow money from the bank, the game then is over immediately. Since the enterprise can't conduct investment for the lack of funds, its expected payment is 0 . And the commercial bank can achieve the expected return of $D r_{f}$ through safe investment. When the enterprise chooses to apply for the loan, the game process will go on to the next stage.

In the second stage of the game, it's up to the commercial bank to make decision 
on whether lending money to enterprise or not. If the bank refuses to make loan to the enterprise, the returns of the bank and enterprise are $D r_{f}$ and 0 respectively. If the bank chooses to make the loan, there will be two different results about the two participants' payments. The first case is that the bank and enterprise can respectively extract $D i$ and $D(r-i)$ if the project investment of enterprise succeeds. Alternatively, when the investment fails, the enterprise will be not able to repay principal and interest of the loan, and the bank will take over the collaterals provided by it, which then leads to their respective returns of $-C$ and $C-D$. The above game playing between the enterprise and bank is shown in figure 1.

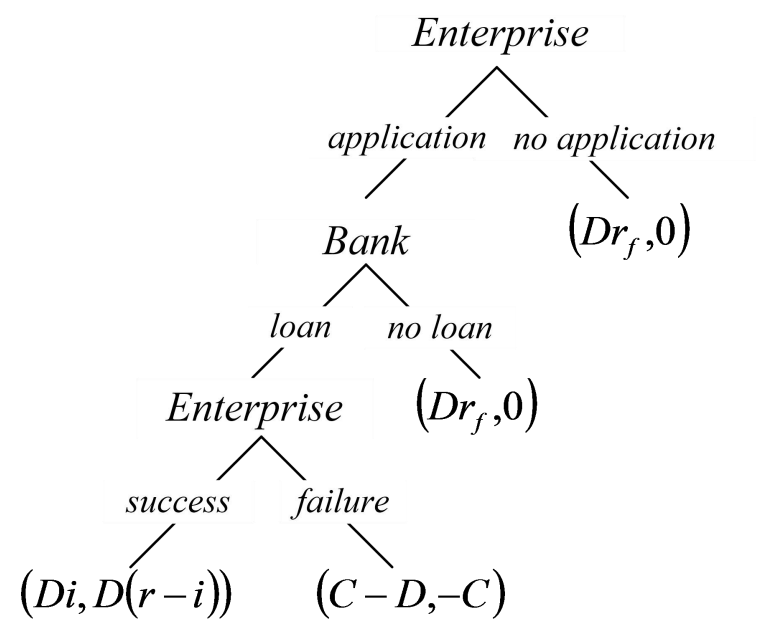

Figure 1. Game Between Small or Medium-sized Enterprise and Commercial Bank

The expected net benefits for enterprise to invest the borrowed funds $D$ in project can be expressed as: $Y=P D(r-i)-(1-P) C$. Since the expected payment for enterprise to give up the loan application is 0 , only when the inequality $Y \geq 0$ holds will the enterprise choose to borrow money from the bank.

For the commercial bank, the expected payment of making loan to the enterprise is $\pi=P D i+(1-P)(C-D)$, and the expected payment of safe investment with the same money is $D r_{f}$. Therefore, the bank will lend money to the enterprise on condition that $\pi$ is high enough to meet $\pi \geq D r_{f}$.

\section{Mathematical Analysis on the Risks and Benefits Caused by Loan Pricing for SMEs}

The expected payment of making loan to SMEs for commercial bank is jointly determined by interest rate and the probability of enterprise's repayment, and the reality shows that the loan interest rate can influence the probability of enterprise's repayment to some extent. In the following part, this paper will firstly analyze the mechanism of action of loan interest rate on enterprise's default risk with mathematical tool on the basis of the above game model. And then the expected revenue function of commercial bank will be built to obtain the optimal loan interest rate.

4.1 Mathematical analysis on the mechanism of action of loan interest rate on enterprise's default risk

It can be seen from the above game analysis that critical condition for enterprise's 
loan application is $Y=P D(r-i)-(1-P) C=0$. According to the basic assumption (1), we can get $R=P D r$, which means that the returns $D r$ for enterprise's successful inestment are negatively related to the probability of investment success denoted by $P$.

To solve the equations:

$$
\begin{aligned}
& \left\{\begin{array}{l}
Y=0 \\
R=P D r
\end{array}\right. \\
& \left\{\begin{array}{l}
P_{0}=\frac{R-C}{D i-C} \\
r_{0}=\frac{R(D i-C)}{D(R-C)}
\end{array} .\right.
\end{aligned}
$$

then we can get:

The solution of equations suggests that there exists a combination of critical values $\left(P_{0}, r_{0}\right)$ for the borrowing enterprise. That is to say, only when the return rate $r$ of successful investment meets $r \geq r_{0}$ will the enterprise apply for the loan from commercial bank, and the probability $P$ of investment success meets $P \leq P_{0}$ at the same time.

Let's assume that the success probabilities $P$ of the optional investment projects faced by enterprise follow the probability distribution in the interval of $[0,1]$ since these projects can form a continuous sequence according to basic assumption (2). In addtion, the probability density function is $f(P)$ and the probability distribution function is $F(P)$. Considering the index of the average probability denoted by $\bar{P}$ of investment success, it is the mean value of the probabilities in the interval of $\left[0, P_{0}\right]$ according to the above analysis, which can be expressed as follows:

$$
\bar{P}=\frac{\int_{0}^{P_{0}} p f(P) d P}{\int_{0}^{P_{0}} f(P) d P}=\frac{\int_{0}^{P_{0}} P f(P) d P}{F\left(P_{0}\right)}
$$

Since $P_{0}=\frac{R-C}{D i-C}$, the average probability $\bar{P}$ of investment success is a function of several variables, including the loan interest rate $i$ and collaterals' value $C$.

Partial derivative of the function $\bar{P}$ from $C$ is:

$$
\frac{\partial \bar{P}}{\partial C}=\frac{f\left(P_{0}\right)}{F^{2}\left(P_{0}\right)} \cdot \frac{R-D i}{(D i-C)^{2}}\left[P_{0} F\left(P_{0}\right)-\int_{0}^{P_{0}} P f(P) d P\right]
$$

Since $\int_{0}^{P_{0}} P f(P) d P<\int_{0}^{P_{0}} P_{0} f(P) d P=P_{0} \int_{0}^{P_{0}} f(P) d P=P_{0} F\left(P_{0}\right)$, and $R-D i>0$ holds true for the SMEs who choose to borrow money from the bank to carry out investment activities, then we can get $\frac{\partial \bar{P}}{\partial C}>0$, which means that the average probability $\bar{P}$ of investment success is positively related to the value $C$ of collaterals provided by enterprise. Therefore, collaterals can play an important role in sending the signal of risk level of the borrowing enterprise, and that's why the bank always asks the borrower to offer enough collaterals before approving the loan.

And the partial derivative of the function $\bar{P}$ from $i$ is:

$$
\frac{\partial \bar{P}}{\partial i}=\frac{f\left(P_{0}\right)}{F^{2}\left(P_{0}\right)} \cdot \frac{-D(R-C)}{(D i-C)^{2}}\left[P_{0} F\left(P_{0}\right)-\int_{0}^{P_{0}} P f(P) d P\right]
$$


Considering that $\int_{0}^{P_{0}} P f(P) d P<P_{0} F\left(P_{0}\right)$, we can get $C>R$ if $\frac{\partial \bar{P}}{\partial i}>0$ holds true. In other words, when the value $C$ of collaterals provided by enterprise is high enough, the average probability $\bar{P}$ of investment success is positively related to the loan interest rate $i$. When the value of collaterals is relatively lower to meet $C<R$, however, the average probability of investment success will go down in pace with the improvement of loan interest rate, namely $\frac{\partial \bar{P}}{\partial i}<0$.

The analysis results above can be explained as follows: when the project investment fails, the bank will take over the collaterals provided by the enterprise since it will be not able to repay principal and interest of the loan. Therefore, the high value of collaterals means the high failure costs for the borrowing enterprise. And when the value of collaterals provided by enterprise is high enough, the enterprise will make investment decision carefully and invest the borrowed money in low-risk project with a high success probability. In addition, it will not make high-risk investment even though the loan interest rate is very high. However, since the SMEs in China always lack effective collaterals, and information asymmetry exists between commercial bank and enterprises, the bank tends to set relatively higher loan interest rates for thses SMEs to cover the high credit risks. As a result, the financing costs of the enterprise rise, which then compels the enterprise to invest money in high-risk and high-return project with a lower success probability to realize the expected payment. In conclusion, with the increasing of loan interest rate, many low-risk enterprises and high-quality projects will exit from the credit market, and the funds will be obtained by high-risk enterprises and invested in risky projects, namely, the adverse selection and moral hazard in the credit market will occur.

\subsection{Mathematical analysis on maximizing expected revenue of commercial bank}

Since the expected payment of lending money to the enterprise for commercial bank is jointly determined by interest rate and the probability of enterprise's repayment, it can be expressed as:

$$
\pi=P D i+(1-P)(C-D)
$$

When considering the average probability $\bar{P}$ of investment success, the expected payment of commercial bank can be expressed as:

$$
\bar{\pi}=\frac{\int_{0}^{P_{0}}[P D i+(1-P)(C-D)] f(P) d P}{\int_{0}^{P_{0}} f(P) d P}=\bar{P} D i+(1-\bar{P})(C-D)
$$

The partial derivative of the function $\bar{\pi}$ from $i$ is:

$$
\frac{\partial \bar{\pi}}{\partial i}=D \bar{P}+[D(1+i)-C] \frac{\partial \bar{P}}{\partial i}
$$

Suppose that the value $C$ of collaterals provided by borrowing enterprise is constant and meets $C<R$, which is reasonable since the SMEs always can't offer enough collaterals to the bank, then the average probability of investment success is negatively related to the loan interest rate, namely $\frac{\partial \bar{P}}{\partial i}<0$. In addition, considering that the inequality $C<D(1+i)$ holds for the existence of credit risks of bank's loan 
business, we can therefore get $[D(1+i)-C] \frac{\partial \bar{P}}{\partial i}<0$. According to the expression (1), the effects of change in loan interest rate $i$ on the expected payment $\bar{\pi}$ of commecial bank can be divided into two parts: income effect $D \bar{P}$ and risk effect $[D(1+i)-C] \frac{\partial \bar{P}}{\partial i}$. Specifically, when the loan interest rate $i$ increases by a unit, the expected payment $\bar{\pi}$ will increase by units of $D \bar{P}$, while the average probability $\bar{P}$ of investment success will decrease by units of $\left|\frac{\partial \bar{P}}{\partial i}\right|$, which then results in a decrease of $\left|[D(1+i)-C] \frac{\partial \bar{P}}{\partial i}\right|$ units in the expected payment of bank. As a result, with regard to how the change in loan interest rate $i$ influence the expected payment $\bar{\pi}$ of commecial bank, there are three scenarios as follows:

(1) When the value $D \bar{P}$ of interest rate's income effect is greater than the absolute value $\left|[D(1+i)-C] \frac{\partial \bar{P}}{\partial i}\right|$ of risk effect, we can get $\frac{\partial \bar{\pi}}{\partial i}>0$, which means that the expected payment $\bar{\pi}$ of commercial bank will go up in pace with the improvement of loan interest rate $i$.

(2) When the value $D \bar{P}$ of income effect is less than the absolute value $\left|[D(1+i)-C] \frac{\partial \bar{P}}{\partial i}\right|$ of risk effect, the inequality $\frac{\partial \bar{\pi}}{\partial i}<0$ will hold, meaning that the expected payment $\bar{\pi}$ will go down in pace with the improvement of loan interest rate $i$.

(3) When the value $D \bar{P}$ of income effect is equal to the absolute value $\left|[D(1+i)-C] \frac{\partial \bar{P}}{\partial i}\right| \quad$ of risk effect, we can get $\frac{\partial \bar{\pi}}{\partial i}=0$. At this moment, the maximum expected payment of commercial bank is reached, and the corresponding loan interest rate is the optimal one for the bank.

Since $\frac{\partial D \bar{P}}{\partial i}=D \frac{\partial \bar{P}}{\partial i}<0$, the value $D \bar{P}$ of the income effect is a decreasing function of loan interest rate $i$. The partial derivative of the function $[D(1+i)-C] \frac{\partial \bar{P}}{\partial i}$ from interest rate $i$ is:

$$
\partial\left\{[D(1+i)-C] \frac{\partial \bar{P}}{\partial i}\right\} / \partial i=D \frac{\partial \bar{P}}{\partial i}+\frac{\partial^{2} \bar{P}}{\partial i^{2}}[D(1+i)-C]
$$

Considering that the result of second-order derivative of $\bar{P}$ from $i$, namely $\frac{\partial^{2} \bar{P}}{\partial i^{2}}$, is so complicated that it is difficult to determine whether the value of $\frac{\partial^{2} \bar{P}}{\partial i^{2}}$ is positive or negative. According to previous empirical research results and the realities, $\frac{\partial^{2} \bar{P}}{\partial i^{2}} \leq 0$ is set to be ture here, which means that the average probability of investment 
success will go down at an accelerated speed in pace with the improvement of loan interest rate $^{1}$. And because the inequalities $\frac{\partial \bar{P}}{\partial i}<0$ and $C<D(1+i)$ hold true, the result of expression (2) is less than 0 . That is to say, the value $[D(1+i)-C] \frac{\partial \bar{P}}{\partial i}$ of risk effect is a decreasing function of loan interest rate $i$, and the absolute value $\left|[D(1+i)-C] \frac{\partial \bar{P}}{\partial i}\right|$ of risk effect is therefore an increasing function of loan interest rate $i$.

On the premise of having taken into consideration the value scopes of income effect and risk effect, the above analysis suggests that the absolute value $\left|[D(1+i)-C] \frac{\partial \bar{P}}{\partial i}\right|$ of risk effect will eventually be greater than the value $D \bar{P}$ of income effect with the increasing of loan interest rate, and then we can get $\frac{\partial \bar{\pi}}{\partial i}<0$. Therefore, as the figure 2 shows, there exits an optimal loan interest rate $i^{*}$ for commercial bak to reach the maximum expected payment $\bar{\pi}^{*}$.

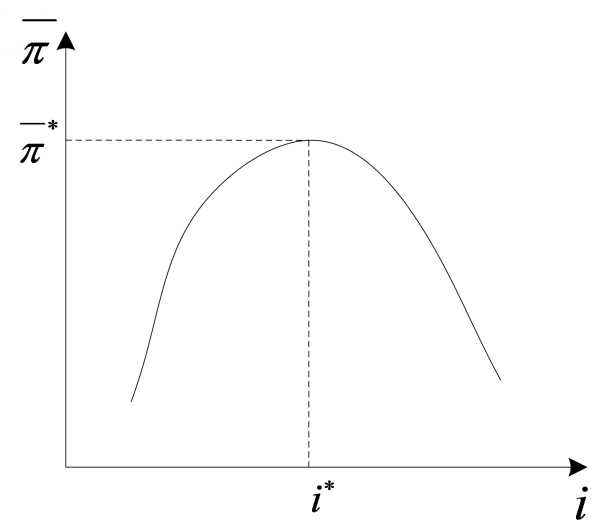

Figure 2. Relationship Between Bank's Expected Returns $\bar{\pi}$ and Loan Rate $i$

\section{Conlusions}

Currently, financing difficulties are the foremost factor of hindering the healthy development of SMEs in China. Only when the financing problem is solved effectively can the SMEs achieve a further development. In the background that the commercial bank enters the business of making loan to SMEs, and RMB interest rate is gradually liberalized, the commercial bank in China is now facing a big test on its ability of loan pricing for SMEs. It is quite necessary for the bank to properly price the loan for SMEs, which can contribute to realizing the maximization of its revenues as well as reducing the default risk of SMEs.

Under the assumption that other variables remain unchanged, the expected payment of making loan to SMEs for commercial bank is jointly determined by

\footnotetext{
${ }^{1}$ Since it is difficult to obtain the combination of SMEs' loan interest rates and default rates, the data of enterprises' default rates in bond market is introduced here to represent the expected loan default rates in reference to the research of Friedson, etc. (1997), Michael and Larry (1999). It can be found that the default rate of bonds will rise at an accelerated speed roughly as the interest rate increases, the expected loan default rate is therefore set to go up at an accelerated speed in pace with the improvement of loan interest rate.
} 
interest rate and the probability of enterprise's repayment, and the loan interest rate can influence the probability of enterprise's repayment to some extent. According to the analysis of this paper, several conclusions are obtained as follows:

(1) The average probability of investment success is positively related to the value of collaterals provided by enterprise. For the SMEs who always lack effective collaterals, their default risk will go up in pace with the improvement of loan interest rate.

(2) The effects of change in loan interest rate on the expected payment of commecial bank can be divided into two parts: income effect and risk effect. And when the value of income effect is equal to the absolute value of risk effect, the maximum expected returns of the bank will be reached.

(3) Under a certain condition, the absolute value of risk effect will eventually be greater than the value of income effect with the increasing of loan interest rate. Therefore, there exits an optimal loan interest rate for commercial bak to realize the revenue maximization.

According to the above analysis, in order to effectively control credit risks of SMEs and maximize returns, commercial bank should try to perfect SMEs loan business by taking many measures. For example, commercial bank ought to innovate enthusiastically on mortgage system to enrich the scope of effective collaterals for SMEs. And then the bank can prevent enterprise from investing in the risky project by means of asking the enterprise to offer collaterals with sufficient value. Besides, commercial bank is advised to improve the system of loan pricing to properly price the loan for SMEs. Specifically, the bank should offer different loan interset rates instesd of the same rate to different SMEs according to their specific conditions, such as the credit rating, loan amount, collateral value, asset-liability ratio and so on.

\section{References}

[1] Martin S. Fridson, M. Christopher Garman, Sheng Wu. Real Interest Rates and the Default Rates on High-yield Bonds [J]. Journal of Fixed Income, 1997, 7(2): 29-34

[2] Helmut B. Screening vs. Rationing in Credit Markets with Imperfect Information [J]. American Economic Review, 1985, 75(4): 850-855

[3] Ewert R, Schenk G, Szczesny A. Determinants of Bank Lending Performance in Germany [J]. Schmalenbach Business Review, 2000, 52(4): 344-362.

[4] Michael F, Larry H. Developing and Implementing Commercial Loan Pricing Models [J]. The Journal of Lending\&Credit Risk Management, 1999, 81(10): 48-53

[5] Liu Chenxi. An Empirical Analysis on Factors Affecting Commercial Rate Floating Amount-Basing on data from public listing companies [D]. Southwestern University of Finance and Economics, 2012 (In Chinese)

[6] Wei Jianguo, Zhu Chun. Study on Identification and Management of Credit Risk of Loan in Village Banks [J]. Journal of Huazhong Agricultural University, 2013(4): 36-41 (In Chinese)

[7] Jairaj Gupta, Nicholas Wilson, Andros Gregoriou, Jerome Healy. The value of operating cash flow in modelling credit risk for SMEs[J]. Applied Financial Economics . 2014 (9)

[8] Pingzhong Lin. Game Analysis of SME Financing[J]. Journal of Financial Risk Management . 2012 (04) 